\title{
Use of iPad/iPods with Individuals with Autism and other Developmental Disabilities: A Meta-analysis of Communication Interventions
}

\author{
Nouf Alzrayer • Devender R. Banda • Rajinder K. Koul
}

Received: 5 May 2014 / Accepted: 7 May 2014 / Published online: 24 May 2014

(C) Springer Science+Business Media New York 2014

\begin{abstract}
We conducted a meta-analysis to determine the impact of using tablet-based devices on the communication skills of individuals with autism and developmental disabilities. A total of 15 studies were reviewed to determine the effectiveness of the intervention on communication skills. The results showed that tablet-based devices, especially iOS devices (i.e., iPad and iPod Touch) were highly effective in increasing the communication skills of individuals with autism and developmental disabilities. Also, the results provided evidence that several participants were able to continue communicating using the devices and to use them in novel contexts. Furthermore, caregivers have positive perceptions of using iOS-based speech-generating devices for communication skills. Results are discussed and implications for practice and future research are provided.
\end{abstract}

Keywords Autism $\cdot$ Developmental disabilities · Communication skills $\cdot \mathrm{iPad} / \mathrm{iPods} \cdot$ Augmentative and alternative communication $\cdot$ Speech-generating devices

Autism spectrum disorder (ASD) is a neurodevelopmental disorder that includes different subtypes such as autism, Asperger's syndrome, and pervasive developmental disorder

\footnotetext{
N. Alzrayer

Department of Educational Psychology and Leadership College of Education, Texas Tech University, PO Box 41071, Lubbock,

TX 79409, USA

D. R. Banda $(\triangle)$

Department of Educational Psychology and Leadership, Texas Tech University, 2500 Broadway St, Lubbock, TX 79409, USA

e-mail: devender.banda@ttu.edu

R. K. Koul

Department of Speech, Language, Hearing Sciences, Texas Tech University Health Sciences Center, 3601, 4th Street, 2A300, Lubbock, TX 79409, USA
}

not otherwise specified (PDD-NOS) (Centers for Disease Control and Prevention [CDC], 2014; Llaneza et al. 2010). Based on the CDC's recent surveillance report (2014), 1 in every 68 children is diagnosed with autism in the USA. In addition to challenging behaviors, children with autism display deficits in social and communication skills. Communication deficits consist of the inability to communicate nonverbally (e.g., making eye contact, gesturing, and pointing) and verbally (e.g., initiating, maintaining, developing, and terminating communicative interactions) (Carpenter 2013). The severity of impaired communication skills vary substantially from one person to another. Some children diagnosed with autism are nonverbal and others, on the other hand, can produce words either intelligibly or unintelligibly (Crissey 2011). Some investigators reported that between 50 and $59 \%$ of individuals with autism are nonverbal, indicating that they are unable to meet their daily communicational needs (Chiang 2008; Koul et al. 2001).

Deficit in communicative abilities have negative impacts on multiple aspects of an individual's life. Research shows that speech and language impairments are associated with challenging behaviors (Matson et al. 2013; Walker and Snell 2013). For example, Chiang (2008) reported that most children with autism who have communication deficits use challenging behaviors as a way to communicate in their school settings. Not replacing problem behaviors with alternative methods to communicate in the early ages of life tend to lessen the chance of learning functional communication skills (Walker and Snell 2013). Also, communication skills deficits affect several adaptive behaviors, such as daily living skills and social skills (Park et al. 2012), and prevent individuals from succeeding in multiple domains in life, such as educational outcomes, vocational accomplishments, social network, and relationships (Walker and Snell 2013).

Enhancing communication skills tends to have positive effects on adaptive skills and helps to decrease problem behaviors (Chiang 2008; Walker and Snell 2013). Matson et al. 
(2013) indicate that young children with autism and with high communication skills have better social skills and exhibit fewer challenging behaviors than those with severe deficits in communication skills. Improving communication skills also improves joint attention (e.g., Charlop-Christy et al. 2002; Prelock et al. 2011).

One of the most effective methods that are used to improve communication skills in children with autism is augmentative alternative communication (AAC) intervention (e.g., Baxter et al. 2012; Cafiero and Delsack 2007). AAC refers to strategies that are used to either support existing speech or replace natural speech and/or written communication (Beukelman and Mirenda 2013). The most common AAC methods that have shown success in improving communication skills for individuals with autism are manual signs (MS), picture exchange communication system (PECS), and speech-generating devices (SGD) (Couper et al. 2014; Ganz et al. 2012; Lorah et al. 2013; van der Meer et al. 2012a, 2012c).

Recently, several handheld multipurpose electronic devices ${\text { (Apple } \mathrm{iPad}^{\mathrm{TM}} \text {, iPod Touch }}^{\mathrm{TM}}$, iPhone ${ }^{\mathrm{TM}}$, and Google Android $^{\mathrm{TM}}$ ) have been used for communication purposes. The most frequently reported devices in the literature are both iPad and iPod Touch. iPad/iPod Touch-based SGDs have several advantages compared to other AAC systems (e.g., MS and PECS), such as social acceptance (Lorah et al. 2013), affordability (McNaughton and Light 2013), portability (Sigafoos et al. 2013), and availability (Shane et al. 2012). In contrast, there are some downsides in this type of technology, such as very limited alternative access methods, lack of trained professionals as service providers, and often diverting the focus from communication goals to other purposes (e.g., entertainment) (McNaughton and Light 2013). There are about 150 apps for AAC purposes that run on $\mathrm{iPad} / \mathrm{iPod}$ Touch-based SGD, as well as iPhone (Alliano et al. 2012). New communication apps are being developed and tested continuously. With an increased use of these communication apps, several AAC intervention studies have been conducted using iPad/iPod Touch-based SGDs during the past 5 years.

Kagohara et al. (2013) conducted a systematic review of 15 studies that used iOS-based devices with individuals with autism and other developmental disabilities. The review focused on teaching several skills including academic, communication, employment, leisure, and transition skills. Eight of 15 studies targeted improving communication skills in 25 participants with developmental disabilities and autism. Seven studies used iPod Touch and one study used iPad. The studies targeted different types of verbal behaviors, one study focused on tacting skills and seven others focused on manding skills. The results of this review indicated that iOSbased devices improved the communication skills of individuals with developmental disabilities and autism. However, the review not only include communication, but also other skills mentioned above. The review also indicated the need for more research on the area of using iOS-based devices to improve different types of verbal behaviors (e.g., mand, tact, and intraverbal). To date, no review has specifically analyzed iPod/iPad or other tablet-based devices to improve communication skills in children with autism and other developmental disabilities. Due to the emergence of new technologies, there is a critical need for more empirical results on the use of iOSbased devices and apps as an AAC system to improve communication skills. Thus, the present study aims to conduct a review of multipurpose handheld devices with communication apps and their impact on communication in individuals with autism and other developmental disabilities. In addition, this study plans to analyze the maintenance, generalization, and social validity of aspects of these interventions.

\section{Method}

Search Procedures and Inclusion Criteria

We conducted an electronic search using EBSCOhost Web (all databases) and ERIC. The terms used to search for studies are: using iPads for communication, iOS devices and communication, autism and iPads/iPods, autism and iOS, Proloquo2Go and autism, SGD and iOS, and tablet-based computers and autism. The electronic search resulted in 316 abstracts which were narrowed down to 122 abstracts after preliminary screening. The first and the second author reviewed 122 abstracts and selected studies that met the inclusion criteria.

We used the following criteria for inclusion in the study: (a) used a tablet-based AAC app as an intervention, (b) included participants with a diagnosis of autism and/or developmental disabilities, (c) focused on improving communication skills, (d) was conducted using a single-subject research design, and (e) was published in a peer-reviewed journal. Also, the most frequently published authors in this area were contacted by the first author for unpublished articles or articles in press; four studies were included through this method (Couper et al. 2014; van der Meer et al. 2012b, 2013; Lorah et al. 2013). In addition, articles that were referenced in previous studies were examined. Two studies were selected from the reviewed studies included in Kagohara et al. (2013) systematic review. Overall, 15 studies met the criteria which were published between 2011 and 2014.

The studies were published in different types of peerreviewed journals. They include, Journal of Developmental and Physical Disabilities, Journal of Developmental Neurorehabilitation, Research in Autism Spectrum Disorders, Journal of Augmentative and Alternative Communication, Journal of Special Education Technology, Research in Developmental Disabilities, and EvidenceBased Communication Assessment and Intervention. 


\section{Data Extraction and Coding}

The reviewed studies were coded into the following categories for further analysis: (a) number of participants, age/gender, diagnosis, communication skills, and behavior problems; (b) research purpose; (c) method (e.g., preference stimuli assessments, apps, iOS-based devices, settings, trainers, design, interventions, inter-observer agreement, and procedural integrity); (d) results; (e) effect size (e.g., percentage of nonoverlapping data points [PND] and average); (f) follow-up; $(\mathrm{g})$ social validity; and $(\mathrm{h})$ generalization.

\section{PNDs Calculations and Interrater Agreement}

PNDs were calculated for each participant in the 13 studies by the first author. Although we included Rayner (2013) and Sigafoos et al. (2013) for review, we did not calculate the PNDs for these studies because there was no graph available for Rayner's study and cumulative frequencies were used in Sigafoos et al. (2013) making it difficult to calculate PNDs because of ceiling effects. The PND score is the percentage of data points in the intervention phase that do not overlap with the highest data point in the baseline phase (Scruggs et al. 1987). The studies that compared between multiple treatments, PNDs were calculated for each treatment. Also, PNDs were calculated for each dependent variable for studies that measured multiple target behaviors. For Flores et al. (2012), there was no baseline; we calculated PNDs by using the picturebased system as baseline because the authors considered them as standard intervention. The criteria that have been set by (Scruggs et al. 1986) were used to determine the effectiveness of the iOS-based SGD intervention, such as the PNDs that ranged between 91 and $100 \%$ indicated high effect size, PNDs ranged between 71 and $90 \%$ indicated moderate effect, PNDs that ranged between 50 and $70 \%$ indicated minimal effect size, and the PNDs that were at $50 \%$ or below indicated no effect on the dependent variables. The Interrater agreement was calculated for $30 \%$ of the PNDs (four studies) by the second author. The formula that was used to determine the PNDs Interrater agreement was dividing the lower PND by the higher PND and multiplying the score by $100 \%$. The Interrater agreement between the two raters was $98 \%$ (range 90 to $100 \%$ ).

\section{Results}

Participants

Age and Disabilities Fifty two participants ( 7 females, 45 males) were included in a total of 15 studies (Table 1). The age range was from 3 to 23 years, with an average of 8 years and 4 months. Most of the participants were at the school-age level, $(n=20)$ age ranged between 3 and 5, $(n=22)$ age ranged between 6 and 12, and $(n=9)$ age ranged between 13 and 17 years. Only one adult female (23 years) was a participant in one study; however, the participant was excluded from the study as there was no progress as a result of the intervention (van der Meer et al. 2011). There was a diverse range of disabilities; autism (61\%); autism with moderate to severe intellectual disabilities (ID) (23\%); and ID (9\%). In addition, autism existed with other disorders, such as epilepsy (5\%), obsessive-compulsive disorder and attention deficit hyperactivity disorder ( $3 \%$ ), and multiple disabilities (ID and orthopedic impairment) (1.9\%).

Communication Skills Ten studies reported the participants' scores in the communication domain of the Vineland Adaptive Behavior Scales-Second edition (Sparrow et al. 2013). The participants' age equivalence on the communication-sub domain: receptive skills ranged between 3 months and 3 years, 11 months $(n=26)$; on expressive communication skills ranged between 1 month and 2 years, 3 months $(n=30)$; on written communication skills ranged between 1 month and 6 years, 9 months $(n=26)$; and on fine motor skills ranged between 8 months and 4 years, 1 month $(n=15)$. Researchers in one of the studies mentioned age equivalence of communication skills on the Vineland Adaptive Behavior Scales-II in general: two participants scored age equivalence of 1 year old, 2 months; one participant age equivalence of 1 year, 4 months; and another one scored 1 year, 3 months (van der Meer et al. 2012a).

Challenging Behaviors Participants in 5 of the 15 studies exhibited challenging behaviors including aggression, selfinjury, hitting, kicking, eloping, and slapping (Sigafoos et al. 2013; van der Meer et al. 2011, 2012b; Kagohara et al. 2012). An adult participant in one of the studies expressed her needs/ wants by crying (van der Meer et al. 2011).

Previous Experience with IOS-Based Devices Researchers in three studies reported that participants were familiar with using iPad/iPod Touch for both tacting and manding (Achmadi et al. 2012; Kagohara et al. 2012) prior to interventions. For example, in Kagohara et al. (2012) studies, investigators targeted tacting items. One male and another female participant had previous experience with using iOS-based devices for communication (van der Meer et al. 2013). The remaining 44 participants had no exposure to iOS-based devices prior to conducting the intervention.

\section{Settings}

The studies were conducted in different settings including schools, therapy rooms, and mixed settings. Seven studies 


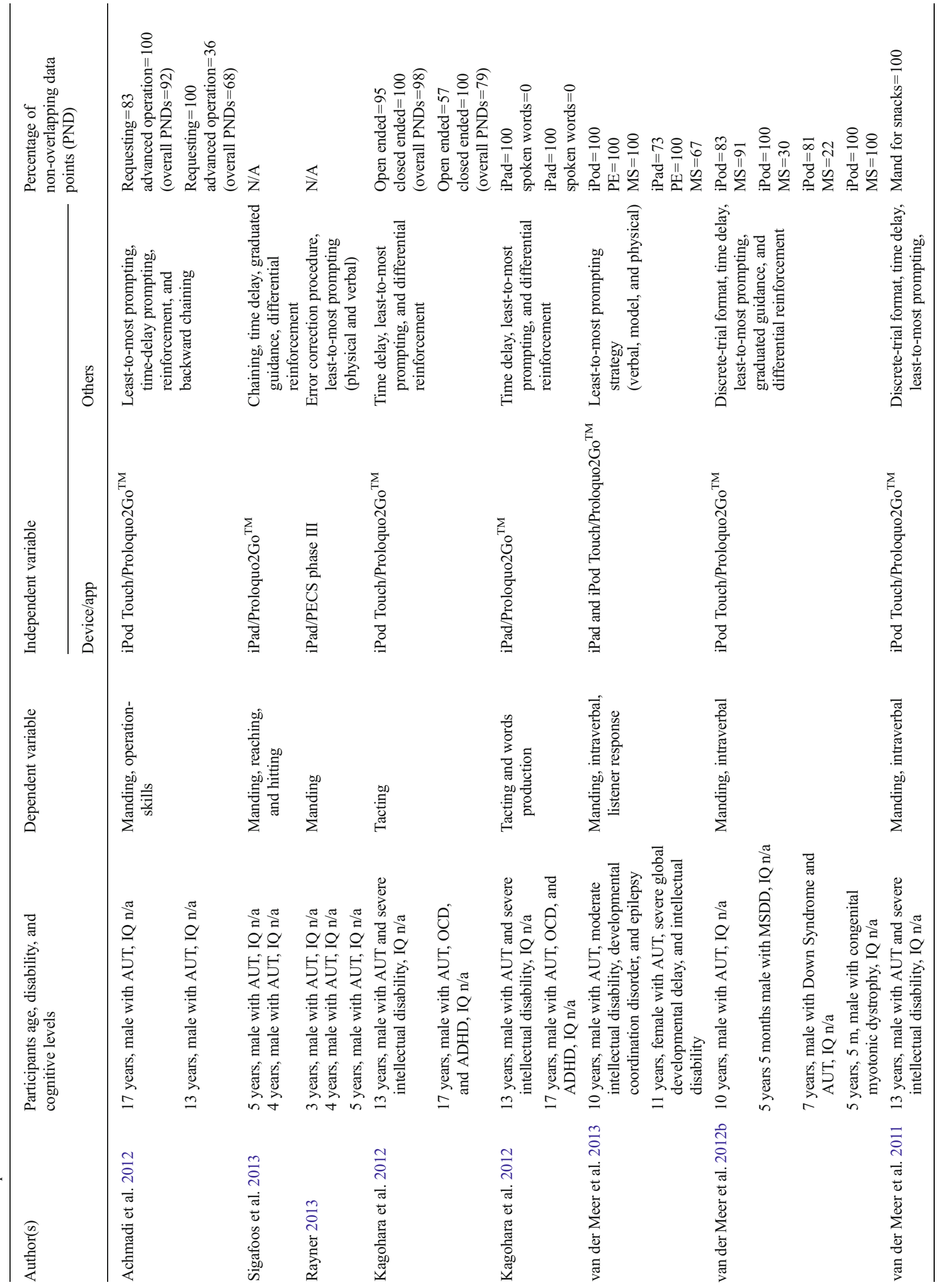




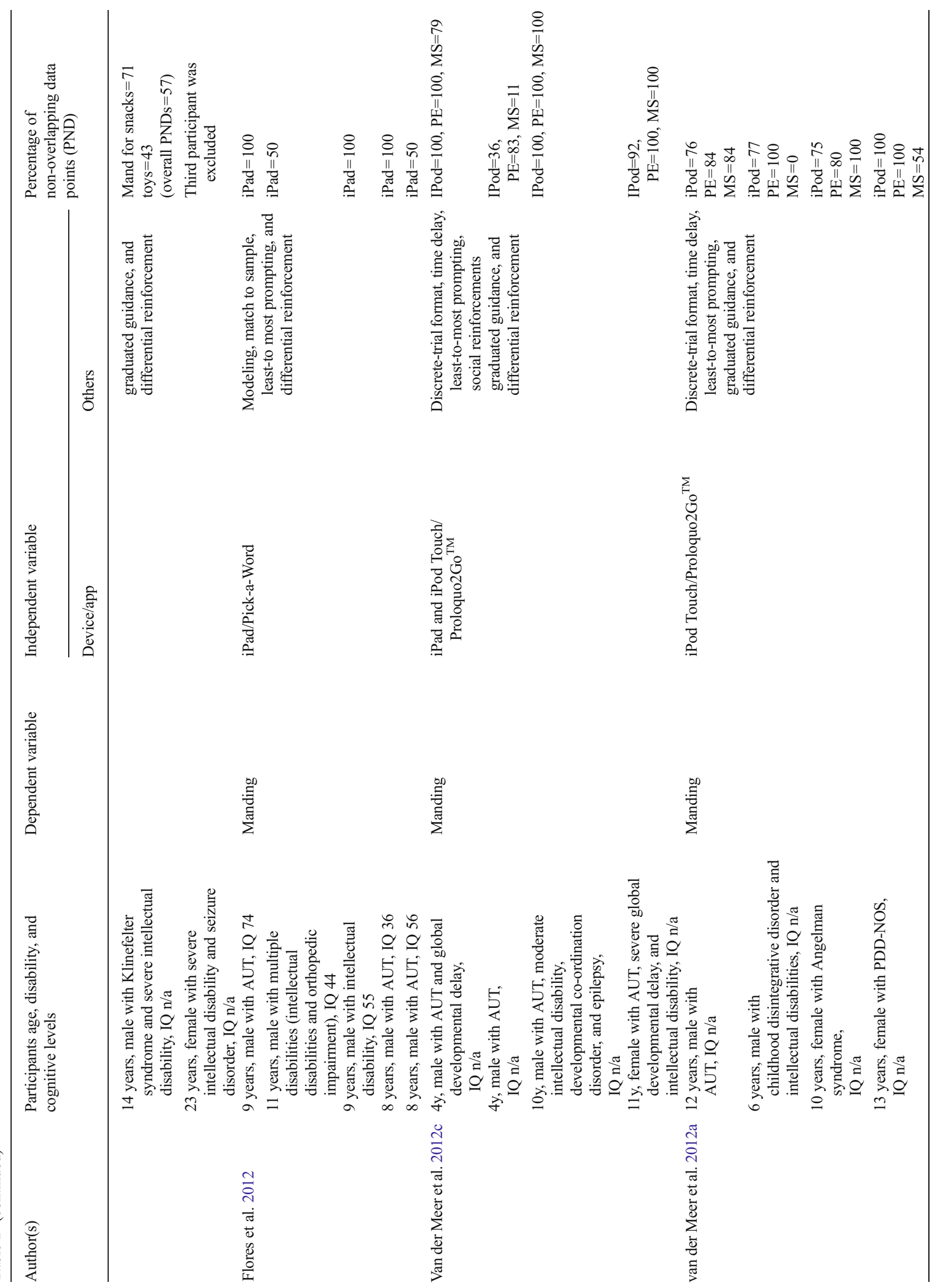




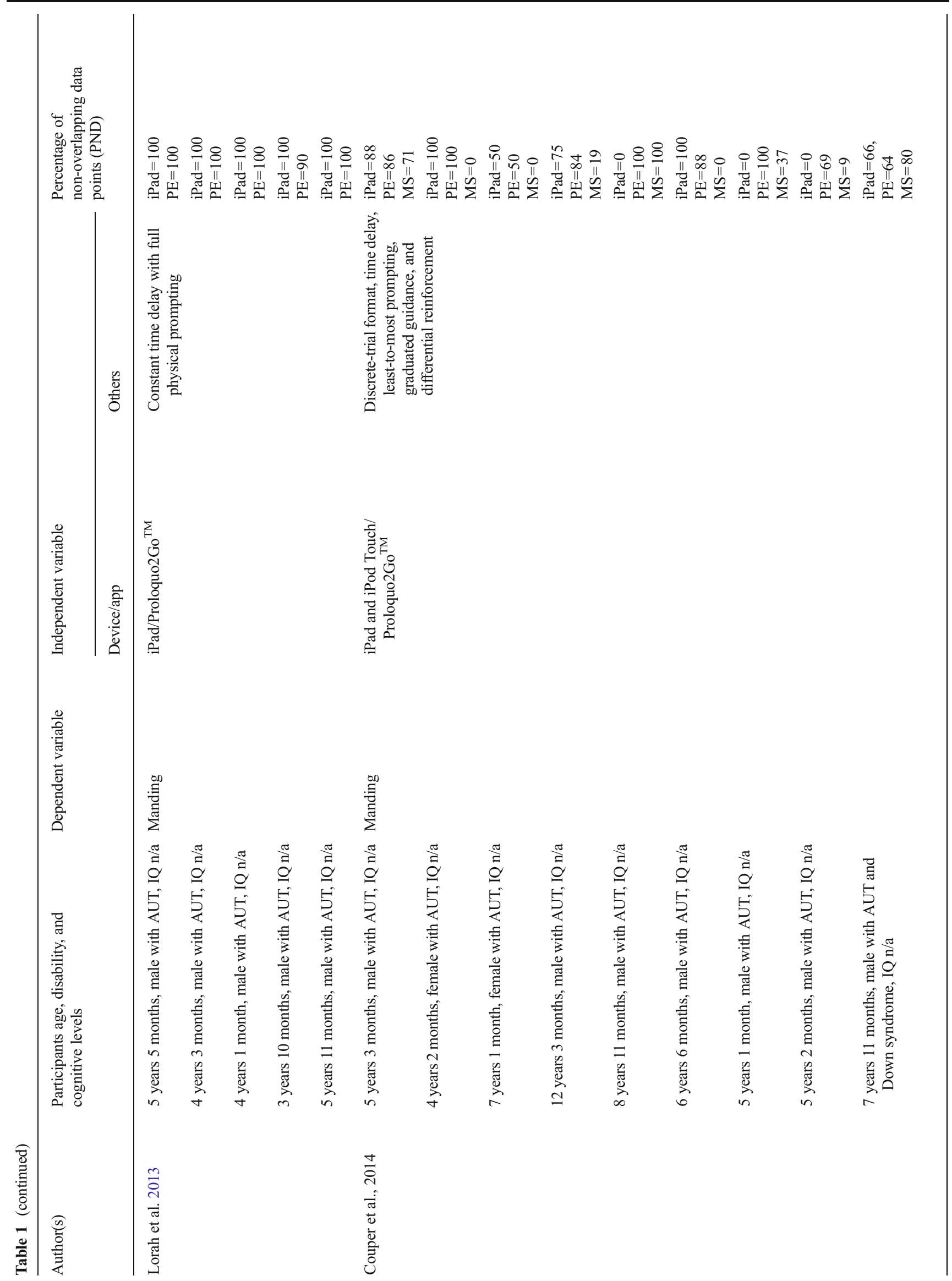




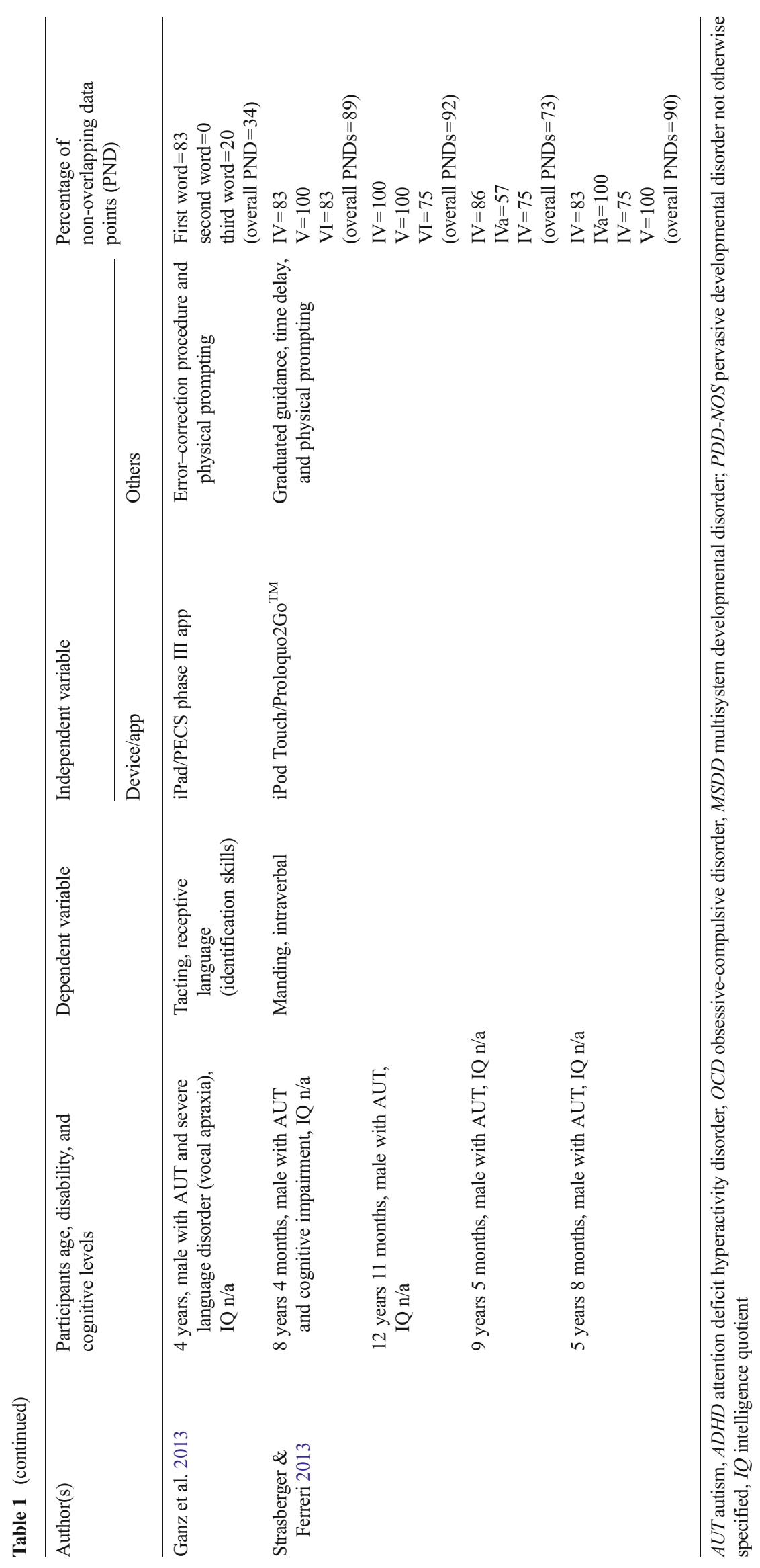


were conducted in school settings, both public and special education schools (Achmadi et al. 2012; Kagohara et al. 2012; van der Meer et al. 2011, 2012b; Lorah et al. 2013; Strasberger and Ferreri 2013). Five studies were in different places in therapy settings, such as the university clinic (Sigafoos et al. 2013), private therapy room in a rehabilitation center (Rayner 2013; Ganz et al. 2013), university-sponsored summer program (Flores et al. 2012), and therapy room in a childcare center for children with developmental disabilities (van der Meer et al. 2012a). A total of three studies were conducted in mixed settings (e.g., school, home, and therapy room) (van der Meer et al. 2012c, 2013; Couper et al. 2014)

\section{Intervention}

Target Communication Behaviors All of the 15 studies either focused on one or more verbal behaviors. Seven studies focused on teaching single-step manding skills (e.g., touching a specific icon on the display seen) with using iOS-based devices (Sigafoos et al. 2013; Rayner 2013; van der Meer et al. 2012a, 2012c; Lorah et al. 2013; Couper et al. 2014; Flores et al. 2012). Six studies focused on multiple verbal behaviors: single-step manding and intraverbal skills (e.g., answer questions by touching icons on the display screen) (van der Meer et al. 2011, 2012b, 2013); single-step tacting, manding, receptive language (identification) skills (e.g., touching the targeted icon when presenting with an preferred object) (Ganz et al. 2013); and single-step tacting skills (e.g., touching the targeted icon when presented with a picture card) (Kagohara et al. 2012). One study targeted improving manding skills by teaching the participants to perform multiple steps when using the iPod Touch (Achmadi et al. 2012). These steps consisted of turning on the device, unlocking it, touching the icon folder (e.g., snacks and toys), and then touching the specific preferred item (e.g., cookies). In Strasberger and Ferreri (2013) study, the targeted behaviors was multiple steps mand and intraverbal. For example, the participants were expected to mand and respond to questions by completing a two-step sequence response (e.g., touch category symbol and touch specific symbol).

Types of iOS-Based Devices, Apps, and Symbols All of the studies used different types of iOS-based devices. Six studies used iPod Touch that was placed inside an iMainGo 2 speaker case as a modification for the sound of the device (Achmadi et al. 2012; van der Meer et al. 2011, 2012a, 2012b; Strasberger and Ferreri 2013; Kagohara et al. 2012), six studies used iPads (Sigafoos et al. 2013; Flores et al. 2012; Lorah et al. 2013; Rayner 2013; Ganz et al. 2013; Kagohara et al. 2012), and three other studies used both iPad and iPod Touch (van der Meer et al. 2012c, 2013; Couper et al. 2014).
As for the software, a majority of studies (12 of 15) have used Proloquo2 $\mathrm{Go}^{\mathrm{TM}}$ as their AAC intervention. In two studies, investigators have used PECS Phase III software (Ganz et al. 2013; Rayner 2013). In one study, Flores et al. (2012), used pictures from Boardmaker ${ }^{\circledR}$ software and loaded them in iOSbased software called "Pick-a-Word".

With regards to display, only one study included a twolevel page: home page and the second page for specific icons (Achmadi et al. 2012). In a total of seven studies, they used one-level page that contained icons with full sentences when making requests (e.g., I want to play with the ball) (van der Meer et al. 2011, 2012a, 2012b, 2012c; Sigafoos et al. 2013; Couper et al. 2014; Strasberger and Ferreri 2013). On the other hand, four studies have used one-word icons when manding or tacting items (Ganz et al. 2013; Kagohara et al. 2012; van der Meer et al. 2013). In Flores et al. (2012) study, the authors used both word and phrases icons to request for preferred items.

The number symbols on the display screen of iOS-based devices ranged from 2 to 18 symbols. Four studies used three symbols of preferred items on the display screen (Achmadi et al. 2012; van der Meer et al. 2011, 2012b; Sigafoos et al. 2013). Several other studies used varied number of symbols on the display screen from 2 to 18 symbols. In addition, several studies used distracter symbols on the display screen to assess the participants' abilities to discriminate between targeted symbols and others (van der Meer et al. 2011, 2012a, 2012b, 2013; Couper et al. 2014; Ganz et al. 2013; Strasberger and Ferreri 2013; Kagohara et al. 2012). Four other studies on the other hand, used only targeted symbols (Achmadi et al. 2012; Sigafoos et al. 2013; van der Meer et al. 2012c; Flores et al. 2012).

Preference Assessment Researchers in 12 studies conducted different types of direct and indirect preference assessments before implementing the interventions. In a total of seven studies, investigators used indirect (e.g., asking caregivers to list preferred items) and direct methods (e.g., simultaneous presentation of multiple items without replacement) (van der Meer et al. 2012a, 2012b, 2012c, 2013; Achmadi et al. 2012; Strasberger and Ferreri 2013; Lorah et al. 2013). In four studies, direct preference assessments were used (e.g., free operant procedure) (Couper et al. 2014; Sigafoos et al. 2013; Rayner 2013; Ganz et al. 2013). In one study (van der Meer et al. 2011), investigators asked teachers to list snacks and toys that were highly preferred for each participant (i.e., an indirect assessment).

Training Sessions A total of 12 studies implemented the interventions in a typical manding session format (Achmadi et al. 2012; Sigafoos et al. 2013; Rayner 2013; van der Meer et al. 2011, 2012a, 2012b, 2012c, 2013; Flores et al. 2012; Couper et al. 2014; Lorah et al. 2013; Strasberger and Ferreri 
Table 2 Methodological components

\begin{tabular}{|c|c|c|c|c|c|c|}
\hline Author (s) & Design (s) & $\begin{array}{l}\text { Inter-observer } \\
\text { agreement }\end{array}$ & $\begin{array}{l}\text { Procedural } \\
\text { integrity }\end{array}$ & $\begin{array}{l}\text { Social } \\
\text { validity }\end{array}$ & Maintenance & Generalization \\
\hline Achmadi et al. 2012 & Multiple probe design across participants & $\mathrm{Y}$ & $\mathrm{Y}$ & $\mathrm{N}$ & $\mathrm{Y}$ & $\mathrm{N}$ \\
\hline Sigafoos et al. 2013 & Multiple baseline design across participants & $\mathrm{Y}$ & $\mathrm{Y}$ & $\mathrm{N}$ & $\mathrm{Y}$ & $\mathrm{Y}$ \\
\hline Rayner 2013 & Multiple baseline design across participants & $\mathrm{Y}$ & $\mathrm{Y}$ & $\mathrm{N}$ & $\mathrm{N}$ & $\mathrm{N}$ \\
\hline Kagohara et al. 2012 & Multiple probe design across participants & $\mathrm{Y}$ & $\mathrm{Y}$ & $\mathrm{N}$ & $\mathrm{Y}$ & $\mathrm{N}$ \\
\hline Kagohara et al. 2012 & Multiple probe design across participants & $\mathrm{Y}$ & $\mathrm{Y}$ & $\mathrm{N}$ & $\mathrm{N}$ & $\mathrm{N}$ \\
\hline Van der Meer et al. 2013 & Alternating treatment design & $\mathrm{Y}$ & $\mathrm{Y}$ & $\mathrm{N}$ & $\mathrm{Y}$ & $\mathrm{N}$ \\
\hline Van der Meer et al., 2012b & $\begin{array}{l}\text { Alternative treatment design embedded in } \\
\text { multiple probe across participants design }\end{array}$ & $\mathrm{Y}$ & $\mathrm{Y}$ & $\mathrm{N}$ & $\mathrm{Y}$ & $\mathrm{N}$ \\
\hline Van der Meer et al. 2011 & Delayed multiple probe across participants design & $\mathrm{Y}$ & $\mathrm{Y}$ & $\mathrm{N}$ & $\mathrm{Y}$ & $\mathrm{N}$ \\
\hline Flores et al. 2012 & Alternating treatment design & $\mathrm{Y}$ & $\mathrm{Y}$ & $\mathrm{Y}$ & $\mathrm{N}$ & $\mathrm{N}$ \\
\hline Van der Meer et al., 2012c & $\begin{array}{l}\text { Alternative treatment design embedded into non- } \\
\text { concurrent multiple baseline across participants } \\
\text { design }\end{array}$ & Y & Y & $\mathrm{N}$ & $\mathrm{Y}$ & $\mathrm{N}$ \\
\hline Van der Meer et al., 2012a & $\begin{array}{l}\text { Alternating treatments design was embedded } \\
\text { within each phase of the multiple probe across } \\
\text { participants design }\end{array}$ & $\mathrm{Y}$ & $\mathrm{Y}$ & $\mathrm{N}$ & $\mathrm{Y}$ & $\mathrm{N}$ \\
\hline Lorah et al. 2013 & Alternating treatment design with initial baseline & $\mathrm{Y}$ & $\mathrm{Y}$ & $\mathrm{N}$ & $\mathrm{Y}$ & $\mathrm{N}$ \\
\hline Couper et al. 2014 & $\begin{array}{l}\text { Alternating treatment design embedded in non- } \\
\text { concurrent multiple baseline across participants } \\
\text { design }\end{array}$ & $\mathrm{Y}$ & Y & $\mathrm{N}$ & $\mathrm{Y}$ & $\mathrm{N}$ \\
\hline Ganz et al. 2013 & Multiple baseline design across target words & $\mathrm{Y}$ & $\mathrm{Y}$ & $\mathrm{N}$ & $\mathrm{N}$ & $\mathrm{N}$ \\
\hline Strasberger and Ferreri 2013 & Multiple baseline design across participants & $\mathrm{Y}$ & $\mathrm{Y}$ & $\mathrm{Y}$ & $\mathrm{Y}$ & $\mathrm{Y}$ \\
\hline
\end{tabular}

2013). The manding session was based on B.F. Skinner's analysis of verbal operant by presenting the participants with preferred items (motivating operations), requesting to have access to these items by using AAC systems (manding verbal operant), and reinforcing the response by providing the requested item (specific reinforcement). Researchers in three studies implemented interventions based on Skinner's analysis of tact verbal operant, which means presenting nonverbal discriminative stimulus (e.g., picture of a cat), verbally responding by using AAC systems (e.g., cat), and providing general reinforcement (e.g., good job) (Ganz et al. 2013; Kagohara et al. 2012). In three studies, other verbal operants (e.g., intraverbal) were also imbedded in manding session (van der Meer et al. 2012b, 2013; Strasberger and Ferreri 2013) by providing the participant with verbal discriminative stimulus (e.g., "would you like a snack?"), answering the question with using AAC systems, and providing general reinforcement.

Naturalistic format training sessions (i.e., intervention is embedded in the participants' daily activities) is another crucial area that was analyzed in this review. Only four studies introduced their intervention in the participants' daily routines. For example, Flores et al. (2012) run the manding sessions during snack time, Sigafoos et al. (2013) and Couper et al. (2014) implemented the treatment during play time, and van der Meer et al. (2011) introduced the sessions during leisure/snack activity.
IOS-Based Interventions vs. Other Interventions Several studies compared the effects of using several AAC systems (SGD, MS, PCS) on verbal behaviors. Four studies compared between two AAC systems (MS, SGD) (van der Meer et al. 2012b), (SGD, PECS) (Rayner 2013), (SGD, PCS) (Flores et al. 2012), and (SGD, PE) (Lorah et al. 2013). Four other studies compared between three AAC systems (SGD, MS, PE) (van der Meer et al. 2012a, 2012c, 2013; Couper et al. 2014). The implementation of the three AAC systems (SGD, MS, PE) was counterbalanced to prevent carryover effects.

Instructional Procedures The studies implemented numerous instructional procedures to teach their participants to use iOSbased devices as an AAC system. Seven studies used systematic instructional package (e.g., time delay, least-to-most prompting, graduated guidance, and differential reinforcement) and discrete-trial training (van der Meer et al. 2011, 2012a, 2012b, 2012c; Couper et al. 2014; Kagohara et al. 2012). Two studies used error correction procedure and least-to-most prompting (physical and verbal) (Ganz et al. 2013; Rayner 2013). Seven of the 15 studies used different instructional procedures: least-to-most prompting, time delay, backward chaining, and reinforcement (Achmadi et al. 2012); chaining, time delay, graduated guidance, and reinforcement (Sigafoos et al. 2013); least-to-most prompting strategy (van der Meer et al. 2013); modeling, match to sample, least-to- 
most prompting, and differential reinforcement (Flores et al. 2012); graduated guidance, time delay, and physical prompting (Strasberger and Ferreri 2013); and constant time delay prompt fading with full physical prompting (Lorah et al. 2013).

Experimental Designs All of the 15 studies in this review implemented single-subject designs specifically, multiple baseline and probe designs and alternative treatment designs. Most studies combined two single-subject designs in order to demonstrate functional control and effectiveness of interventions. Overall, researchers in all of the studies used sound experimental designs (with multiple participants and/or behaviors) to establish functional relation between dependent and independent variables. For various designs, please refer to Table 2.

PNDs The effectiveness of the using iOS-based devices was calculated for 13 studies, with a total of 46 participants. The effect size varied from high effect ( $90 \%$ and above) to no effect at all (below $50 \%$ ). Twenty three participants out of 46 showed that iPod Touch/iPad-based SGD intervention was highly effective (PNDs from 91 to $100 \%$ ) in improving the communication skills. For 12 participants, there was moderate improvement in their communication (PNDs from 73 to $90 \%$ ). Six participants showed that the iOS-based SGD as AAC intervention had minimal effect on communication skills (PNDs from 50 to $70 \%$ ). The intervention has no effects on five participants (PNDs from 0 and $36 \%)$.

PNDs were compared across age groups ( 3 to 12 vs. 13 years and higher) and there was no difference across age groups. IOS-based SGD showed to be a highly effective AAC intervention for individuals with a wide range of disabilities with different severity levels. For instance, $48 \%$ of the participants with diagnosis of autism, $38 \%$ of the participants diagnosed with autism and moderate to severe developmental disabilities, and $14 \%$ of the participants who were diagnosed with other disabilities (e.g., congenital myotonic dystrophy).

Maintenance and Generalization Eleven studies included maintenance/follow-up sessions in their experimental designs. In four comparison studies between AAC systems (SGD, PECS, MS), the participants were able to maintain their ability to communicate using iOS devices during follow-up sessions.

As for generalization, only 2 of 15 studies assessed the ability of individuals with autism to apply their acquired skills to novel situations. In Sigafoos et al.'s (2013) study, the participants requested to have access to preferred toys by using iPad-based SGD during treatment sessions and were able to generalize their acquired skills across different items (access for a preferred game and mand for preferred snacks).
In another study, the participants had an opportunity to practice their communication skills by using iPod Touch into their classroom during their snack time (Strasberger and Ferreri 2013) and the results revealed their ability to use iPod Touch for manding and answering questions.

Social Validity Only two studies assessed social validity of the intervention. Flores et al. (2012) assessed teachers' perceptions about the existing communication problems and the need for AAC interventions using a pre- and post-questionnaire about the teachers' previous experiences in using iOS-based devices. The pre-questionnaire revealed that the participants were in need for AAC treatments, especially SGD-based AAC. The post-questionnaire, on the other hand, indicated that the teachers and the participants preferred the iPad over the picture communication system, and it was easy to operate for both participants and teachers. Also, the teachers' answers showed that the participants' communication increased after using iPad-based SGD. In another study, Strasberger and Ferreri (2013) administered a post-survey, the Behavioral Intervention Rating Scale (BIRS) (Elliott and Treuting 1991) with three classroom teachers to rate the effectiveness and the acceptability of the intervention. The survey contained 24 questions that were rated on 6-point Likert scale, 6 being the highest and 1 being the lowest. The average rating of all the items for all the three teachers was 4.9 (agree).

\section{Discussion}

The purpose of the review was to analyze the effects of using iOS-based SGDs on the communication skills of individuals with autism and other developmental disabilities. The review also analyzed the participants' abilities to maintain and generalize the acquired skills, as well as parents and teachers' perception of the iOS-based SGD. Several findings are evident from this review.

One of the most important results is that iPad/iPod Touchbased communication intervention has positive effects on communication skills (manding, tacting, and intraverbal). Results for 23 participants showed that the iOS-based SGDs were a highly effective AAC intervention and moderately effective for 12 participants in improving their communication skills. There may be several possible reasons for this type of AAC system to be highly effective, such as voice-output feedback (Couper et al. 2014; Schlosser, Sigafoos, and Koul 2009; Koul and Schlosser 2004; Schlosser et al. in press), less cognitive and motor skills demands (van der Meer et al. 2012a), and high iconic symbols (Koul et al. 2001). Also, the findings show that systematic instructions are the most effective teaching methods in AAC interventions (Sigafoos et al. 2013). Furthermore, in a comparison between iOS-based 
SGDs and other AAC systems (e.g., PECS and MS), individuals with autism and developmental disabilities learned to use iOS devices for communication in few sessions. In addition, preference assessments in several studies revealed that iOSbased SGD was chosen as the preferred method among other AAC systems (e.g., PECS and MS) (van der Meer et al. 2012a, 2012b, 2012c).

Some additional variables need to be considered when interpreting these results. For examples, participants in three of the studies had a previous experience with using iOS devices for communication which might have influenced the study results (van der Meer et al. 2013; Kagohara et al. 2012; Achmadi et al. 2012). Furthermore, in some studies, when researchers compared SGD and other AAC systems, the participants' familiarity with MS and PECS may have influenced the results (Couper et al. 2014).

Results also indicate that iPad/iPod Touch-based SGDs also have positive effects on decreasing challenging behaviors. For example, one participant showed a decrease in physical aggression (hitting) after introducing iPad-based SGD as AAC system (Sigafoos et al. 2013). SGDs may facilitate expressive language skills (Sigafoos et al. 2003). This is consistent with the existing literature that when participants' communication is enhanced through AAC systems, challenging behaviors may decrease because they may have learned a new method to communicate instead of unconventional methods (i.e., challenging behaviors) (Walker and Snell 2013).

Although researchers in many studies did not probe for generalization, the participants were able to use iOS-based SGDs for communication with different items and in different places (Sigafoos et al. 2013; Strasberger and Ferreri 2013). The generalization tactics that were used in these two studies are based on applied behavioral analysis (ABA). In Sigafoos et al.'s (2013) study, the authors used stimulus generalization to prompt the participants' abilities to use the iOS-based device to mand for multiple preferred items. In another study, Strasberger and Ferreri (2013) provided their participants opportunities to use the iOS-based device in their classrooms, which is considered an introduction to natural reinforcement contingencies as a generalization tactic.

In regards to social validity, parents and teachers have reported positive perceptions about iOS-based SGDs. The results of social validity questionnaires revealed that their students/children learned to use the iOS devices faster than other AAC systems (e.g., MS and PECS). According to parents' and teachers' perceptive, not only iOS devices were superior to other systems in fast acquisition, but also in preference and effectiveness (Strasberger and Ferreri 2013; Flores et al. 2012). These results might be because iOS-based SGDs are more appealing, portable, and cost effective compared to other conventional AAC systems (e.g., Couper et al. 2014).
Also, studies that compared iOS-based devices with other AAC systems, participants preferred iOS-based devices for communication instead of pictures or MS.

The review revealed that there are several gaps in literature and future researchers need to address these gaps. None of the 15 studies included having symbolic understanding as participants' inclusion criteria or provide data on the participants' scores on symbol assessments. Information on the participants' ability to distinguish between two-dimension and three-dimension items is critical to select the appropriate AAC system for individuals with complex communication needs (Beukelman and Mirenda 2013).

Researchers in six studies reported data on the effects of iOS-based SGDs on verbal behaviors (tact, intraverbal, and autoclitic), as well as spoken words production (Kagohara et al. 2012; van der Meer et al. 2011, 2013; Ganz et al. 2013; Strasberger and Ferreri 2013); more research is needed in this area. Another area to be investigated is teaching individuals with autism and developmental abilities about operational skill, such as turning on/off the iOS device, navigate multiple page levels, return to the home page, and clear messages in the message box. Moreover, some of these studies included few symbols on the display screen, including distracter symbols, and combing multiple symbols to create sentences (subject, verb, and object) (van der Meer et al. 2012a, 2013; Strasberger and Ferreri 2013; Couper et al. 2014). As for contextual format, there is a critical need for more research in conducting the sessions in individuals' daily activities which is recommended in the area of effective AAC interventions. Also, there are a limited number of Apps that are implemented in the 15 studies (Proloquo2Go, PECS phase III, and Pick-a-Word). Further research need to investigate the effects of other recent apps on communication skills (e.g., Proloquo4Text, TapSpeak Choice LLC, and OneVoice). Another area that needs to be studied is comparing the effectiveness between two to three types of SGDs (e.g., Dynavox, iOS, and Go talk). All of the studies in this review used two types of iOS devices (iPad and iPod Touch); however, no studies included other more recent devices (e.g., iPhone, mini iPad, and other window-based or android devices such as Microsoft Surface Pro 2, Google Nexus 10, and Kindle Fire HDX 7).

Even though the review concluded a list of positive effects of iOS devices on communication skills of individuals with autism and developmental disabilities, the findings need to be considered in the view of some limitations. First, we did not include dissertations or unpublished studies. Second, the results of the studies are based on limited number of studies with participants' ages between 3 to 17 years old, with a variety of disabilities limiting the conclusions. 
Implications for Practitioners

IOS-based devices may benefit both individuals with autism and developmental disabilities to improve their communication skills. It should be noted that before using a tablet-based computer as AAC system for individuals with disabilities, symbol assessments should be conducted to ensure that they have symbolic understanding to benefit from the intervention. At the beginning stage of teaching to use tablet-based computers, it is recommended to train the participants in manding skills in order to pair the device to be a conditioned reinforcer for the individual. Therefore, it is very important to use preference assessment to conduct successful manding sessions. Communication skills are more than expressing needs/wants. Thus, practitioners should train individuals with complex communication needs through a wide variety of verbal behaviors that aim to develop social interactions, relationships with others, and in different contextual settings. Also, individuals with autism and developmental disabilities need to be trained in discrimination among multiple symbols. In order to develop competent communicators, practitioners should train individuals to develop their operational skills to use the AAC device successfully, such as combine multiple symbols to create sentences, navigate through multiple page levels, add/remove icons, turn off/on the device, and erase messages in the message window.

\section{Conclusion}

Overall, the reviewed studies concluded that using iOS-based SGD have positive effects on communication skills of individuals with autism and developmental disabilities. Based on AAC systems comparison studies, iOS-based SGDs surpassed other AAC systems (e.g., MS and PECS). Specifically, iPads are more effective than other tablet-based computers. As for the iOS-based Apps, Proloquo2Go appeared to be the most effective communication app. The results of the review also revealed that systematic instructions are effective in teaching AAC interventions. Further research should focus on using other communication apps that run on a wide range of touchscreen devices to improve multiple types of verbal behaviors.

\section{References}

Achmadi, D., Kagohara, D. M., van der Meer, L., O'Reilly, M. F., Lancioni, G. E., Sutherland, D., et al. (2012). Teaching advanced operation of an iPod-based speech-generating device to two students with autism spectrum disorders. Research in Autism Spectrum Disorders, 6(4), 1258-1264.
Alliano, A., Herriger, K., Koutsoftas, A. D., \& Barlotta, T. E. (2012). A review of $21 \mathrm{iPad}$ applications for augmentative and alternative communication purposes. Perspectives on Augmentative \& Alternative Communication, 21(2), 60-71.

Baxter, S., Enderby, P., Evans, P., \& Judge, S. (2012). Barriers and facilitators to the use of high-technology augmentative and alternative communication devices: a systematic review and qualitative synthesis. International Journal of Language \& Communication Disorders, 47(2), 115-129. doi:10.1111/j.1460-6984.2011.00090.x.

Beukelman, D. R., \& Mirenda, P. (2013). Augmentative and alternative communication: Supporting children and adults with complex communication needs (4th ed.). Glenview, Illinois Paul H. Brookes Publishing Co., Inc. .

Cafiero, J. M., \& Delsack, B. S. (2007). AAC and autism: compelling issues, promising practices and future directions. Perspectives on Augmentative \& Alternative Communication, 16(2), 23-26.

Carpenter, L. (2013). DSM-5 autism spectrum disorder: guidelines and criteria exemplars.

Centers for Disease Control and Prevention. (2014). Prevalence of autism spectrum disorders among children aged 8 years-Autism and Developmental Disabilities Monitoring Network, 11 sites, United States, 2010. Surveillance Summaries. Autism and Developmental Disabilities Monitoring Network Surveillance Year 2010 Principal Investigators. 63(10), 1-21.

Charlop-Christy, M. H., Carpenter, M., Le, L., LeBlanc, L. A., \& Kellet, K. (2002). Using the picture exchange communication system (PECS) with children with autism: assessment of PECS acquisition, speech, social-communicative behavior, and problem behavior. Journal of Applied Behavior Analysis, 35(3), 213-231.

Chiang, H.-M. (2008). Expressive communication of children with autism: the use of challenging behaviour. Journal of Intellectual Disability Research, 52(11), 966-972.

Crissey, P. (2011). Teaching communication skills to children with autism. Verona, Wisconsin: Attainment Company, Inc.

Elliott, S. N., \& Treuting, M. V. B. (1991). The behavior intervention rating scale: development and validation of a pretreatment acceptability and effectiveness measure. Journal of School Psychology, 29(1), 43-51.

Flores, M., Musgrove, K., Renner, S., Hinton, V., Strozier, S., Franklin, S., et al. (2012). A comparison of communication using the apple iPad and a picture-based system. AAC: Augmentative \& Alternative Communication, 28(2), 74-84. doi:10.3109/07434618.2011.644579.

Ganz, J. B., Earles-Vollrath, T. L., Heath, A. K., Parker, R. I., Rispoli, M. J., \& Duran, J. B. (2012). A meta-analysis of single case research studies on aided augmentative and alternative communication systems with individuals with autism spectrum disorders. Journal of Autism and Developmental Disorders, 42(1), 60-74.

Ganz, J. B., Hong, E. R., Goodwyn, F., Kite, E., \& Gilliland, W. (2013). Impact of PECS tablet computer app on receptive identification of pictures given a verbal stimulus. Developmental Neurorehabilitation, (0), $1-6$.

Kagohara, D. M., van der Meer, L., Achmadi, D., Green, V. A., O'Reilly, M. F., Lancioni, G. E., et al. (2012). Teaching picture naming to two adolescents with autism spectrum disorders using systematic instruction and speech-generating devices. Research in Autism Spectrum Disorders, 6(3), 1224-1233.

Kagohara, D. M., van der Meer, L., Ramdoss, S., O’Reilly, M. F., Lancioni, G. E., Davis, T. N., et al. (2013). Using iPods ${ }^{\circledR}$ and $\mathrm{iPads}^{\circledR}$ in teaching programs for individuals with developmental disabilities: a systematic review. Research in Developmental Disabilities, 34(1), 147-156. doi:10.1016/j.ridd.2012.07.027.

Koul, R., \& Schlosser, R. (2004). Effects of synthetic speech output in the learning of graphic symbols of varied iconicity. Disability \& Rehabilitation, 26(21/22), 1278-1285.

Koul, R., Schlosser, R. W., \& Sancibrian, S. (2001). Effects of symbol, referent, and instructional variables on the acquisition of aided and 
unaided symbols by individuals with autism spectrum disorders. Focus on Autism \& Other Developmental Disabilities, 16 (3), 162.

Llaneza, D. C., DeLuke, S. V., Batista, M., Crawley, J. N., Christodulu, K. V., \& Frye, C. A. (2010). Communication, interventions, and scientific advances in autism: a commentary. Physiology \& Behavior, 100(3), 268-276. doi:10.1016/j.physbeh.2010.01.003.

Lorah, E., Tincani, M., Dodge, J., Gilroy, S., Hickey, A., \& Hantula, D. (2013). Evaluating picture exchange and the $\operatorname{iPad}^{\mathrm{TM}}$ as a speech generating device to teach communication to young children with autism. Journal of Developmental \& Physical Disabilities, 25(6), 637-649. doi:10.1007/s10882-013-9337-1.

Matson, J. L., Hess, J. A., \& Mahan, S. (2013). Moderating effects of challenging behaviors and communication deficits on social skills in children diagnosed with an autism spectrum disorder. Research in Autism Spectrum Disorders, 7(1), 23-28.

McNaughton, D., \& Light, J. (2013). The iPad and mobile technology revolution: benefits and challenges for individuals who require augmentative and alternative communication. AAC: Augmentative and Alternative Communication, 29(2), 107-116.

Park, C. J., Yelland, G. W., Taffe, J. R., \& Gray, K. M. (2012). Brief report: the relationship between language skills, adaptive behavior, and emotional and behavior problems in pre-schoolers with autism. Journal of Autism and Developmental Disorders, 42(12), 2761-2766.

Prelock, P. A., Calhoun, J., Morris, H., \& Platt, G. (2011). Supporting parents to facilitate communication and joint attention in their young children with autism spectrum disorders: two pilot studies. Topics in Language Disorders, 31(3), 210-234.

Rayner, C. S. (2013). The finding that three children with ASD were taught to use an iPad PECS app was conclusive, though one participant retained a preference for use of the traditional PECS book. Evidence-Based Communication Assessment \& Intervention, 7(2), 68-72. doi:10.1080/17489539.2013.829274.

Schlosser, R. W., Sigafoos, J., \& Koul, R. K. (2009). Speech output and speech generating devices in autism. In P. Mirenda \& T. Iacono (Eds.), In AAC for Individuals with Autism Spectrum Disorders. Paul H. Brookes: Baltimore, MD.

Schlosser, R. W., Koul, R., Shane, H., Sorce, J., Brock, K., Harmon, A., et al. (in press). Effects of animation on naming and identification across two graphic symbols sets representing actions and prepositions. Journal of Speech, Language, and Hearing Research.

Scruggs, T. E., Mastropieri, M. A., Cook, S. B., \& Escobar, C. (1986). Early intervention for children with conduct disorders: a quantitative synthesis of single-subject research. Behavioral Disorders, 11(4), 260-271.

Scruggs, T. E., Mastropieri, M. A., \& Casto, G. (1987). The quantitative synthesis of single-subject research: methodology and validation. Remedial \& Special Education, 8, 24-52, doi:10.1177/ 074193258700800206.

Shane, H. C., Laubscher, E. H., Schlosser, R. W., Flynn, S., Sorce, J. F., \& Abramson, J. (2012). Applying technology to visually support language and communication in individuals with autism spectrum disorders. Journal of Autism and Developmental Disorders, 42(6), $1228-1235$.

Sigafoos, J., Didden, R., \& O'Reilly, M. (2003). Effects of speech output on maintenance of requesting and frequency of vocalizations in three children with developmental disabilities. AAC: Augmentative and Alternative Communication, 19(1), 37-47. doi:10.1080/ 0743461032000056487.

Sigafoos, J., Lancioni, G. E., O’Reilly, M. F., Achmadi, D., Stevens, M., Roche, L., et al. (2013). Teaching two boys with autism spectrum disorders to request the continuation of toy play using an $\mathrm{iPad}^{\mathbb{B}}$ based speech-generating device. Research in Autism Spectrum Disorders, 7(8), 923-930. doi:10.1016/j.rasd.2013.04.002.

Sparrow, S. S., Cicchetti, D. V., Balla, D. A., DiStefano, C., Greer, F. W., \& Kamphaus, R. W. (2013). Vineland adaptive behavior scalessecond edition. Multifactor modeling of emotional and behavioral risk of preschool-age children, 25(2), 467-476.

Strasberger, S. K., \& Ferreri, S. J. (2013). The effects of peer assisted communication application training on the communicative and social behaviors of children with autism. Journal of Developmental and Physical Disabilities. doi:10.1007/s10882-013-9358-9.

van der Meer, L., Kagohara, D., Achmadi, D., Green, V. A., Herrington, C., Sigafoos, J., et al. (2011). Teaching functional use of an iPodbased speech-generating device to individuals with developmental disabilities. Journal of Special Education Technology, 26(3), 1-11.

van der Meer, L., Didden, R., Sutherland, D., O’Reilly, M., Lancioni, G., \& Sigafoos, J. (2012a). Comparing three augmentative and alternative communication modes for children with developmental disabilities. Journal of Developmental \& Physical Disabilities, 24(5), 451468. doi:10.1007/s10882-012-9283-3.

van der Meer, L., Kagohara, D., Achmadi, D., O’Reilly, M. F., Lancioni, G. E., Sutherland, D., et al. (2012b). Speech-generating devices versus manual signing for children with developmental disabilities. Research in Developmental Disabilities: A Multidisciplinary Journal, 33(5), 1658-1669.

van der Meer, L., Sutherland, D., O’Reilly, M. F., Lancioni, G. E., \& Sigafoos, J. (2012c). A further comparison of manual signing, picture exchange, and speech-generating devices as communication modes for children with autism spectrum disorders. Research in Autism Spectrum Disorders, 6(4), 1247-1257.

van der Meer, L., Kagohara, D., Roche, L., Sutherland, D., Balandin, S., Green, V. A., et al. (2013). Teaching multi-step requesting and social communication to two children with autism spectrum disorders with three AAC options. AAC: Augmentative \& Alternative Communication, 29(3), 222-234. doi:10.3109/07434618.2013.815801.

Walker, V. L., \& Snell, M. E. (2013). Effects of augmentative and alternative communication on challenging behavior: a metaanalysis. AAC: Augmentative \& Alternative Communication, 29(2), 117-131. doi:10.3109/07434618.2013.785020. 